\title{
Esophageal Cancer in Sudan: Demographic and Histopathlogical Variations
}

\author{
Asma Mahir Hamad', Mohamed Elbagir K. Ahmed², Abdulfattah Abdelgadir ${ }^{3}$, \\ Ikhlas B. Suliman ${ }^{4}$ \\ ${ }^{1}$ Sunderland Royal Hospital, Sunderland, UK \\ ${ }^{2}$ College of Medicine, King Khalid University, Abha, KSA \\ ${ }^{3}$ University of Medical Sciences \& Technology, Khartoum, Sudan \\ ${ }^{4}$ Ministry of Health, Khartoum, Sudan \\ Email: mohamedelbagir@live.com
}

How to cite this paper: Hamad, A.M., Ahmed, M.E.K., Abdelgadir, A. and Suliman, I.B. (2017) Esophageal Cancer in Sudan: Demographic and Histopathlogical Variations. Open Journal of Gastroenterology, 7, 124-129.

https://doi.org/10.4236/ojgas.2017.73014

Received: July 26, 2016

Accepted: March 28, 2017

Published: March 31, 2017

Copyright (C) 2017 by authors and Scientific Research Publishing Inc. This work is licensed under the Creative Commons Attribution International License (CC BY 4.0).

http://creativecommons.org/licenses/by/4.0/

\begin{abstract}
Background: Sudan is experiencing a growing cancer problem. Esophageal cancer (EC) is a devastating disease with high mortality. Our objective was to study the demographic factors and histopathological pattern of EC cancer in Khartoum, Sudan. Methods: In a retrospective cross-sectional study, the records and histopathology reports of all patients diagnosed endoscopically as EC and who were referred to Zain center, a reference histopathology center in Khartoum Sudan, were studied over a 6-month period. Descriptive and simple statistics were used for analysis. Results: Out of 74 histopathologically studied patients, 66 (89.2\%) had squamous cell (SCC) cancer (average age $59 \mathrm{y}$, mainly females) and $8(10.8 \%)$ had adenocarcinoma (AC-average age $69 \mathrm{y})$. The female to male ratio is 1.5:1. In females with SCC, the tumors mainly located in the upper and middle thirds of the oesophagus. On the other hand, 6 out of the 8 patients with AC were men, with the tumors located mainly in the lower third. Conclusions: In Khartoum, Sudan, esophageal cancer affects females (predominantly SCC) more than males (predominantly AC). It occurs at a relatively young age, and is predominantly squamous cell in type. No specific risk factors were identified and this needs further studies.
\end{abstract}

\section{Keywords}

Esophagus, Cancer, Histopathology, Sudan

\section{Introduction}

Esophageal cancer (EC) is the 6th most common cause of cancer death worldwide, with around 400,000 deaths in 2012 (5\% of the total) [1]. Worldwide in 2012, there were 14.1 million new cancer cases, 8.2 million cancer deaths, and 
32.6 million people living with cancer within 5 years of diagnosis. Moreover, $57 \%$ ( 8 million) of new cancer cases, $65 \%$ ( 5.3 million) of the cancer deaths and $48 \%$ (15.6 million) of the 5-year prevalent cancer cases occurred in the less developed regions [1].

The two predominant histological subtypes of oesophageal cancer are squamous cell carcinoma (SCC), which is more prevalent in developing countries and adenocarcinoma (AC) is more common in the developed countries [2].

These two forms of oesophageal cancer are etiologically unrelated because adenocarcinoma is primarily associated with gastric reflux and Barrett's Oesophagus [3], whereas squamous cell carcinoma is mainly associated with multiple factors such as smoking, alcohol consumption, hot tea drinking, red meat consumption, poor oral health, low intake of fresh fruit and vegetables, and low socioeconomic status [4]-[9]. The highest incidence is reported in what is so-called the "Asian oesophageal cancer belt" stretching from Eastern Turkey through North-eastern Iran, Northern Afghanistan and Southern Russia [10] [11], and to Northern China. However, Europe and North America show lower rates compared to the Asian belt [12].

In Sudan, earlier reports (1977) showed that the incidence of EC was $1.4 \%$ of all malignant tumors. The disease affected both sexes equally; and was most common at the age group of $50-69$ [13].

In contrast, a recent study (2012) from Gezira province in central Sudan showed that $9.6 \%$ of patients referred for endoscopy proved to have esophageal cancer. Also, greater proportions of women rather than men were affected with the disease [14].

The main objective of this study was to explore the histological pattern and its relation to age and gender in Khartoum, the capital of Sudan.

\section{Methods}

This is a retrospective cross sectional study which was performed with the main aim of studying the histopathological pattern of EC and its relation to gender and age. The records and histopathology reports of all patients diagnosed endoscopically as EC and who were referred to Zein center, a reference histopathology center in Khartoum Sudan, were studied over a 6-month period. The demographic factors were recorded as well as the report of the endoscopy. The endoscopic diagnosis was made in two main endoscopy centers in Khartoum, Biopsies were then sent to the histopathology center, a reference in Khartoum that one of the authors (AA), an experienced pathologist, processed and performed the histopathology diagnosis. Descriptive and simple statistics were used for analysis using SPSS 14 packages.

\section{Results}

We studied 74 histologically proven esophageal cancer (EC) patients, out of whom there were 44 females (59.5\%) and 30 males (40.5\%), constituting a female to male ratio of 1.5:1 
The minimum age affected was 37 years old, whereas the maximum age was 85 years with a mean age of 60 years (SD 9 years)

The peak of the patients with EC was in the age group 65 to 69 years, constituting $40 \%$ of all. Another peak occurred in the age group 50 to 54 years, which constituted only $27 \%$. For patients less than 50 years and over 70 years old, the rates were much less, constituting $2.7 \%$ and $8.1 \%$ respectively (Figure 1 ).

The distribution of the site of EC was found to be equal in both the lower and middle thirds, each of which, making up 29.73\%, whereas the upper third was the most frequently affected site (40.54\% Table 1$)$.

With regard to histological type, Squamous cell carcinoma (SCC) was noticeably the commonest type of EC (89.2\%), compared to adenocarcinoma (AC) which amounted for $10.8 \%$. Adenocarcinoma (AD) was found to be more frequent in males, comprising $75 \%$, whereas it was only $25 \%$ in females. Interestingly, no documentation of Barrett's oesophagus was reported. On the other hand, SCC, occurred predominantly in females (63.6\%), compared to males (36.4\%), a statistically significant difference ( $P$ value 0.036 ) (Figure 2 ). Moreover, SCC was evenly distributed over the different age groups with a slight peak at age group 50 - 54 years, while the $\mathrm{AC}$ was most frequently reported among the age group 75 - 79 years.

Table 1. Distribution of esophageal carcinoma in relation to the site of the tumor.

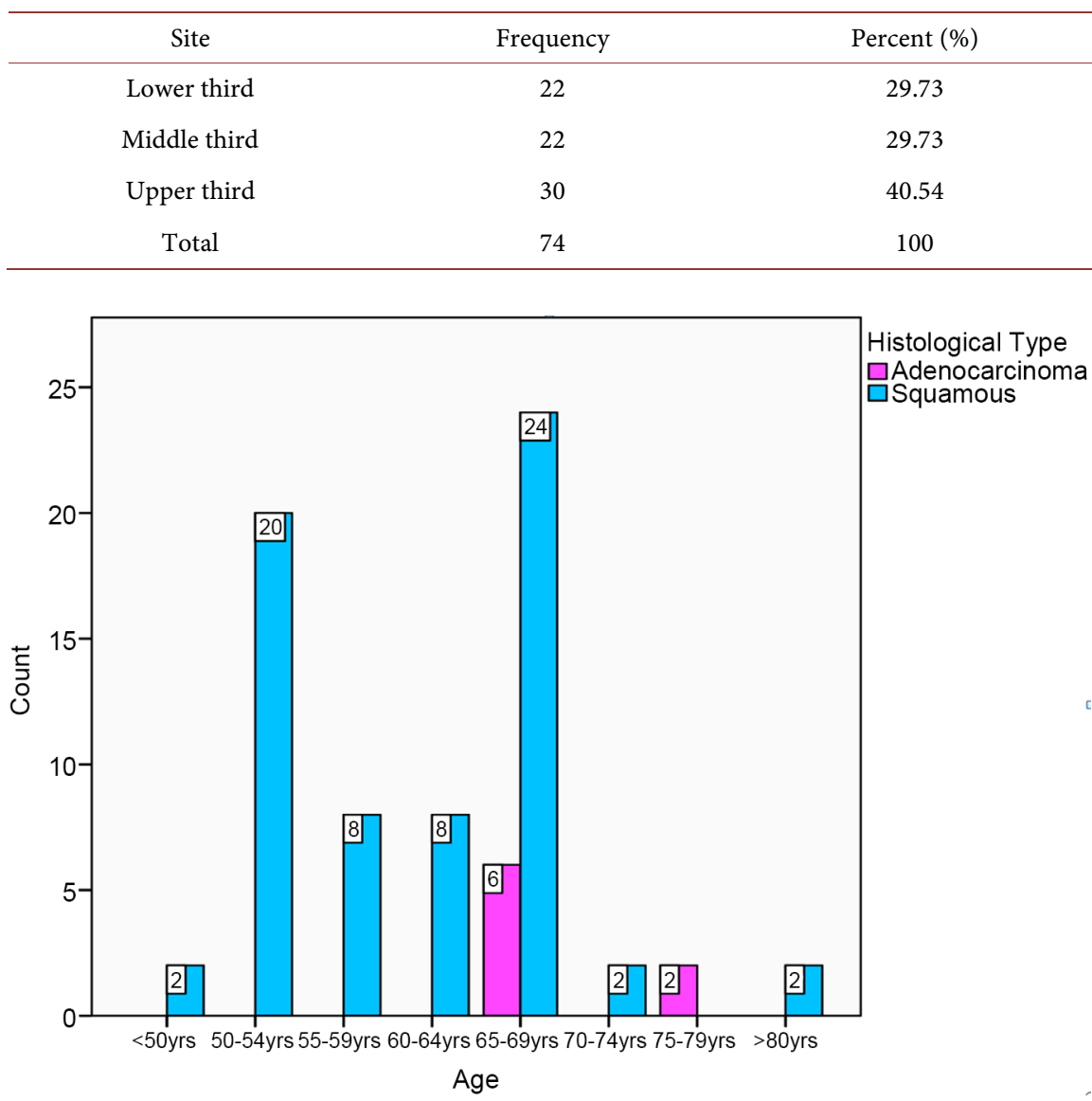

Figure 1. Histological type by age groups. 


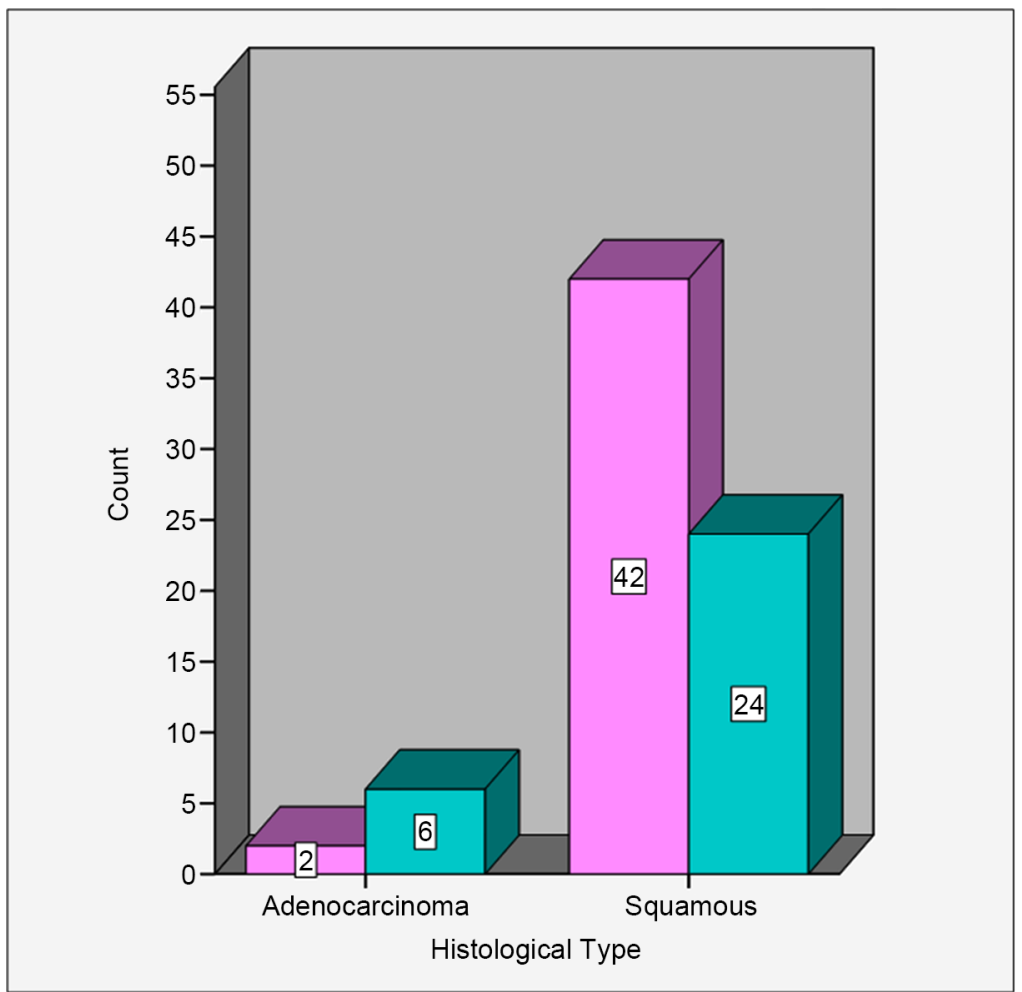

Figure 2. Histological types by gender.

\section{Discussion}

This study in Sudan has demonstrated a distinct gender and histological patterns of EC with female predominance. In contrast, studies in other countries showed that the incidence is $2-4$ times higher in men than in women. In males, the highest incidence of esophageal cancer is observed in Southern Africa [agestandard rate (ASR): 22.3 per 100,000], Eastern Asia (ASR: 20.3 per 100,000), and Eastern Africa (ASR: 14.9 per 100,000). Similarly, these areas are also sites of the highest incidence among females [15].

Several other epidemiologic studies suggested that gender may be an intervening factor for esophageal cancer. Women with esophageal cancer tend to have a better prognosis than men. However, patients with the same clinical features and treatments may have different clinical outcomes, indicating that genetic variants may play an important role in esophageal cancer prognosis [16].

The gender variations documented in this study that women were more affected with SCC at a relatively younger age, while AC was more prevalent among elderly men, are intriguing. Early studies (1977) in Sudan found that men and women were equally affected [13], but our present findings are in agreement with the recent reports from Sudan, confirming female predominance [14]. These gender variations especially female predominance might point towards specific risk factors that prevailed overtime among Sudanese women. These may include dietary and life style changes, but obviously this matter needs further exploration. On the other hand, the most documented risk for AC is Barrett's esophagus complicating longstanding reflux oesophagitis which was shown in pre- 
vious reports [17], however, no documentation of Barrett's esophagus was reported among our patients.

The higher frequency of SCC of the esophagus among Sudanese women presents a significant health problem because the development of the disease can be asymptomatic, resulting in late diagnosis and therefore a poor prognosis. The 5 -year survival of the SCC is less than $10 \%$, a statistic that has remained unchanged over the past 30 years [18].

Furthermore, the risk factor for this serious disease needs further exploration so that preventive measures can be universally implemented.

However, cancer control encompasses a package of diverse interventions aiming at reducing morbidity and mortality with wide variations in costs and potential impact. It has been shown in a recent study from the Netherland that, specifically for current smokers, vegetables and possibly also fruits intake was inversely associated with SCC and AC risk [19].

In general, there is a clear need to develop strategies that will allow early diagnosis of this disease so as to develop clear preventive and better therapeutic approaches leading to reduction in mortality especially in developing countries with limited resources.

A better understanding of the aetiology and molecular mechanisms involved in the development of oesophageal cancer may allow these critical issues to be addressed more effectively [20]. Thus, identification of crucial molecular pathways involved in esophageal adenocarcinogenesis would ultimately improve therapy and facilitate development of new treatment strategies [21].

Unfortunately, taking the variation in epidemiology of EC, especially in developing countries, serious budgetary constraints and competition with the demands of other endemic diseases, cancer control programmes need to make wise choices to maximise the efficacy of any therapeutic or preventive measures [22].

\section{References}

[1] Ferlay, J., Soerjomataram, I., Ervik, M., et al. (2013) GLOBOCAN 2012 v1.0, Cancer Incidence and Mortality Worldwide: IARC CancerBase No. 11 [Internet]. International Agency for Research on Cancer, Lyon.

[2] Sugimura, T., Takahashi, M., Tominaga, S., Trichopoulos, D., Walker, C., Watanabe, S., Welsburger, E., Yamazoe, Y. and Zhao, X. (1997) Food, Nutrition and the Prevention of Cancer: A Global Perspective. American Institute for Cancer Research, Washington DC.

[3] Day, N.E. and Varghese, C. (1994) Oesophageal Cancer. Journal of Cancer Survivorship, 19-20, 43-54.

[4] Gamliel, Z. (2000) Incidence, Epidemiology, and Etiology of Esophageal Cancer. Chest Surgery Clinics of North America, 10, 441-450.

[5] Zhang, H.-Z., Jin, G.-F., and Shen, H.-B. (2012) Epidemiologic Differences in Esophageal Cancer between Asian and Western Populations. Chinese Journal of Cancer, 31, 281-286. https://doi.org/10.5732/cjc.011.10390

[6] Umar, S.B. and Fleischer, D.E. (2008) Esophageal Cancer: Epidemiology, Pathogenesis and Prevention. Nature Clinical Practice Gastroenterology \& Hepatology, 5, 517-526. https://doi.org/10.1038/ncpgasthep1223 
[7] Pennathur, A., Gibson, M.K., Jobe, B.A. and Luketich, J.D. (2013) Oesophageal carcinoma. Lancet, 381, 400-412. https://doi.org/10.1016/S0140-6736(12)60643-6

[8] Mao, W.M., Zheng, W.H. and Ling, Z.Q. (2011) Epidemiologic Risk Factors for Esophageal Cancer Development. Asian Pacific Journal of Cancer Prevention, 12, 2461-2466.

[9] Enzinger, P.C. and Mayer, R.J. (2003) Esophageal Cancer. The New England Journal of Medicine, 349, 2241-2252. https://doi.org/10.1056/NEJMra035010

[10] Rasool, S., Ganai, B.A., Syed Sameer, A. and Masood, A. (2012) Esophageal Cancer: Associated Factors with Special Reference to the Kashmir Valley. Tumori, 98, 191-203.

[11] Li, J.Y. (1982) Epidemiology of Esophageal Cancer in China. National Cancer Institute Monograph, 62, 113-120.

[12] Pennathur, A., Gibson, M.K., Jobe, B.A. and Luketich, J.D. (2013) Oesophageal Carcinoma. Lancet, 381, 400-412. https://doi.org/10.1016/S0140-6736(12)60643-6

[13] Boulos, P.B. and El Masri, S.H. (1977) Carcinoma of the Oesophagus in the Sudan. Tropical and Geographical Medicine, 29, 150-154.

[14] Moawia, E.M., Daffala, O.A., Elgaili, M.E. and Nagla, G. (2012) Predominance of Females with Oesophageal Cancer in Gezira, Central Sudan. Arab Journal of Gastroenterology, 13, 174-177. https://doi.org/10.1016/j.ajg.2012.06.012

[15] Denver, H. and Iqbal Parker, M. (2002) Oesophageal Cancer in Africa. IUBMB Life, 53, 263-268. https://doi.org/10.1080/15216540212643

[16] Crane, S.J., Locke, G.R., Harmsen, W.S., et al. (2008) Survival Trends in Patients with Gastric and Esophageal Adenocarcinomas: A Population-Based Study. Mayo Clinic Proceedings, 83, 1087-1094. https://doi.org/10.4065/83.10.1087

[17] Lagergren, J., Bergström, R., Lindgren, A. and Nyrén, O. (1999) Symptomatic Gastroesophageal Reflux as a Risk Factor for Esophageal Adenocarcinoma. The New England Journal of Medicine, 340, 825-831. https://doi.org/10.1056/NEJM199903183401101

[18] Shimada, Y., Imamura, M., Watanabe, G., et al. (1999) Prognostic Factors of Oesophageal Squamous Cell Carcinoma from the Perspective of Molecular Biology. British Journal of Cancer, 80, 1281-1288. https://doi.org/10.1038/sj.bjc.6990499

[19] Steevens, J., Schouten, L.J., Goldbohm, R.A. and van den Brandt, P.A. (2011) Vegetables and Fruits Consumption and Risk of Esophageal and Gastric Cancer Subtypes in the Netherlands Cohort Study. International Journal of Cancer, 129, 2681-2693. https://doi.org/10.1002/ijc.25928

[20] Koppert, L.B., Wijnhoven, B.P., van Dekken, H., et al. (2005) The Molecular Biology of Esophageal Adenocarcinoma. Journal of Surgical Oncology, 92, 169-190. https://doi.org/10.1002/jso.20359

[21] Jankowski, J.A., Wright, N.A., Meltzer, S.J., et al. (1999) Molecular Evolution of the Metaplasia-Dysplasia-Adenocarcinoma Sequence in the Esophagus. American Journal of Pathology, 154, 965-973. https://doi.org/10.1016/S0002-9440(10)65346-1

[22] Zhang, Y.W. (2013) Epidemiology of Esophageal Cancer. World Journal of Gastroenterology, 19, 5598-5606. https://doi.org/10.3748/wjg.v19.i34.5598 
Submit or recommend next manuscript to SCIRP and we will provide best service for you:

Accepting pre-submission inquiries through Email, Facebook, LinkedIn, Twitter, etc. A wide selection of journals (inclusive of 9 subjects, more than 200 journals)

Providing 24-hour high-quality service

User-friendly online submission system

Fair and swift peer-review system

Efficient typesetting and proofreading procedure

Display of the result of downloads and visits, as well as the number of cited articles Maximum dissemination of your research work

Submit your manuscript at: http://papersubmission.scirp.org/

Or contact ojgas@scirp.org 